\title{
OBSERVATIONS CONSISTENT WITH AUTOCRINE STIMULATION OF HYBRIDOMA CELL GROWTH AND IMPLICATIONS FOR LARGE-SCALE ANTIBODY PRODUCTION
}

\author{
Gyun Min Lee ${ }^{1}$, Mark S. Kaminski ${ }^{2}$ and Bernhard O. Palsson ${ }^{1 *}$ \\ ${ }^{1}$ Cellular Biotechnology Laboratory, Department of Chemical Engineering and ${ }^{2}$ Department of \\ Internal Medicine, University of Michigan, Herbert H. Dow Building, Ann Arbor, MI 48109
}

\begin{abstract}
Existence of autocrine growth factors (aGFs) may influence the serum requirement for growth of hybridoma cells and thus significantly influence process economics. For the thurine hybridoma cell line $\mathrm{S} 3 \mathrm{H} 5 / \gamma 2 \mathrm{bA} 2$, critical inoculum density (cID) and serum requirement for growt were inversely related for cultivation in both $T$ fiasks and spinner flasks. In spinner flasks, an inoculum density of $10^{6} \mathrm{cells} / \mathrm{ml}$ was necessary for the cells to grow in RPMI 1640 medium without serum supplement, and an inoculum density of $10^{3} \mathrm{cell} / \mathrm{ml}$ was necessary in RPMI 1640 medium with $10 \%$ serum. In T fasks, where the local cell density is higher than in spinner flasks, an inoculum density of $10^{6}$ cells $/ \mathrm{ml}$ was necessary for the cells to grow in RPMI 1640 medium without serum supplement, and an inoculum density of $1 \mathrm{cell} / \mathrm{ml}$ was also necessary in RPMI 1640 medium with $10 \%$ serum. Further, immobilized cells at high local cell density could grow under conditions where cells in $T$ flasks at corresponding overall cell density could not grow. The cells at high inoculum density were less sensitive to shear induced by mechanical agitation than the cells at low inoculum density. Taken together these observations support the existence of secreted aGF(s) by the hybridoma cell line used. Since the specific MAb production rate was independent of cultivation method and inoculum density the existence of autocrine growth factors would suggest that the use of immobilized cells should improve the economics of MAb production.
\end{abstract}

\section{INTRODUCTION}

Autocrine stimulation of cell growth has been described as the molecular and cellular basis for several malignancies (Sporn and Roberts, 1985; Cooper, 1990). The well known critical inoculum density (cID) requirement for growth in the culture (Tharakan and Chau, 1986; Velez et al., 1986; Lee et al., 1989) has led to the hypothesis that hybridoma cells produce autocrine growth factors (aGFs) needed for their own growth. Some supporting evidence for this phenomenon has been reported; spent serum-free medium was found to accelerate growth rate of hybridoma cell line 167.4G5.3 (Ozturk and Palsson, 1990).

The possible existence of aGFs has significant implications for large-scale cultivation of hybridoma cells. The most expensive item for large-scale cultivation is serum. If the aGFs are also contained in the serum, elimination of serum requirement (by adaptation, genetic manipulation, aGF supplementation, etc) might be desirable. Detailed mechanistic understanding and identification of a particular aGF may become necessary but the first step would be to establish aGF requirement phenomenologically.

We therefore set out to address three hypotheses. First, if the aGFs are serum contained and are produced by the cells at low levels, then there should exist an inverse relationship between the cID and the serum level. If the serum level is low then high inoculum densities would be required to make enough aGF to enable growth, whereas high serum levels should satisfy the aGF requirement and allow growth at low inoculum densities. Second, if an aGF is secreted then the mode of cultivation would influence the cID. Cultivation methods that have high local cell densities (such as $\mathrm{T}$ flask where the cells sit in close proximity on the bottom of the flask, or cells immobilized in a matrix) should exhibit lower cID as compared to cultivation methods in which 
the cells are distributed uniformly over the culture medium (such as in suspension, or in a spinner flask). Third, cells grown at high cell density would be exposed to high levels of aGFs which are known to stimulate cell growth. Cells that are actively growing are less susceptible to shear than cells in lag (Petersen et al., 1988) and stationary phases (Lee et al., 1988a; Petersen et al., 1988). Therefore, cells at high cell density may be less sensitive to shear induced by mechanical agitation than cells grown at low cell density. Further, an important issue from an antibody production point of view is whether the specific monoclonal antibody (MAb) productivity is altered by aGFs. Interleukin 6 (IL-6), which may be an aGF in hybridoma cells, is known to stimulate immunoglobulin synthesis in lymphoid cells (Hirano et al., 1986; Balkwill, 1989).

An affirmative answer to these hypotheses is suggestive of the presence of aGF but a conclusive answer can only be obtained by identifying the particular aGF responsible for the growth stimulation. However, phenomenological results are important for MAb production. Here, we show that the answer to the three hypotheses addressed is affirmative, thus justifying a search for the particular aGF responsible. Further, we show that for the cell line we used growth rate and the specific MAb production rate are decoupled.

\section{MATERIALS AND METHODS}

Cell line, medium and culture maintenance The murine hybridoma used was $\mathrm{S} 3 \mathrm{H} 5 / \gamma 2 \mathrm{bA} 2$. The antibody produced by this cell line is an IgG2b, directed against the idiotype of murine lymphoma 38C13 (Bergman and Haimovich, 1977). The cell culture medium was RPMI 1640 (Sigma, St.Louis, MO) supplemented with $10 \%$ fetal bovine serum (FBS, Gibco Laboratories, Grand Island, NY), 100 units $/ \mathrm{ml}$ of penicillin, and $100 \mu \mathrm{g} / \mathrm{ml}$ of streptomycin (Sigma). The cells were maintained in T $25 \mathrm{~cm}^{2}$ plastic cell culture flasks (Bellco Glass, Inc., Vineland, NJ) at $37^{\circ} \mathrm{C}$ in a humidified $\mathrm{CO}_{2}$ incubator. The cells were diluted 1:5 with fresh medium every other day.

Cell cultures Exponentially growing cells were inoculated into $25 \mathrm{~cm}^{2} \mathrm{~T}$ flasks and spinner flasks (Bellco) at the inoculum density in the range of $10^{2}$ to $10^{6}$ cells $/ \mathrm{ml}$. The total working volumes of $T$ flasks and spinner flasks were $10 \mathrm{ml}$ and $50 \mathrm{ml}$, respectively. RPMI medium with various FBS concentrations was used. For static culture, thirty $\mathrm{T}$ flasks were inoculated at each initial cell density and three flasks were taken each time for assays. Since a significant amount of $\mathrm{S} 3 \mathrm{H} 5 / \gamma 2 \mathrm{bA} 2$ cells attach at the bottom of $\mathrm{T}$ flasks during the culture, it was necessary to sacrifice $T$ flasks to obtain accurate cell counts (Lee et al., 1988). Exponentially growing cells were also inoculated into 6 well plates at the inoculum density in the range of 1 to 10 cells $/ \mathrm{ml}$ to determine a critical inoculum density required for growth in media with various serum concentrations. For agitated cultures, cell cultures in spinner flasks were carried out at two agitation speeds of 100 and $200 \mathrm{rpm}$. All the experiments were performed in a humidified $\mathrm{CO}_{2}$ incubator adjusted to $37^{\circ} \mathrm{C}$.

Immobilization The hybridoma cells were entrapped in a gel matrix of calcium alginate as follows: (1) Exponentially growing cells were centrifuged at $1000 \mathrm{rpm}$ for $10 \mathrm{~min}$. After discarding the supernatant, cells were resuspended in buffered saline $(0.9 \% \mathrm{NaCl}$ buffered with $2.2 \mathrm{mM}$ HEPES at $\mathrm{pH} 7.4$ with $150 \mathrm{mg} / \mathrm{l}$ glucose) and the stock sodium alginate solution ( $2 \%$ in $0.9 \%$ $\mathrm{NaCl}$ ) to form a final concentration of approximately $10^{5} \mathrm{cells} / \mathrm{ml}$ in $1.0 \%$ sodium alginate. One $\mathrm{ml}$ of a mixture of viable cells and alginate solution was packed in a syringe. (2) The mixture was added dropwise to $1.3 \% \mathrm{CaCl}_{2}$ buffered with $13 \mathrm{mM}$ HEPES. Eighty one uniform-sized gel particles (ca. $2 \mathrm{~mm}$ in diameter) were obtained in this manner. (3) Gel-entrapped hybridoma cells were allowed to stand for 10 minutes in order to achieve proper gelation. The supernatant solution was removed by decantation, and the immobilized cells were washed 3 times with buffered saline. (4) Gel particles were resuspended in $0.05 \%(\mathrm{w} / \mathrm{v})$ poly-L-lysine (PLL, molecular weight 22,000 , Sigma) for 6 minutes to form the membrane. This PLL treatment is necessary when RPMI 1640 is used, because high concentrations of phosphate in RPMI medium will dissolve the calcium alginate gels (Lee and Palsson, 1990). The supernatant solution was removed by decantation, and the immobilized cells were washed 3 times with fresh RPMI 1640 medium with $1 \%$ FBS. Twenty gel particles were transferred to $75 \mathrm{~cm}^{2} \mathrm{~T}$ flask containing $30 \mathrm{ml}$ of RPMI 1640 medium with $1 \%$ FBS. The initial cell concentration was ca. $800 \mathrm{cells} / \mathrm{ml}$ of medium.

Analytical methods Cell growth was monitored by counting viable cells with a hemocytometer. The viable cell population was distinguished from dead cells by the trypan blue dye exclusion method. The specific growth rates were determined from the slope of the logarithmic viable cell concentration versus time during the exponential growth period. The cell growth in the 

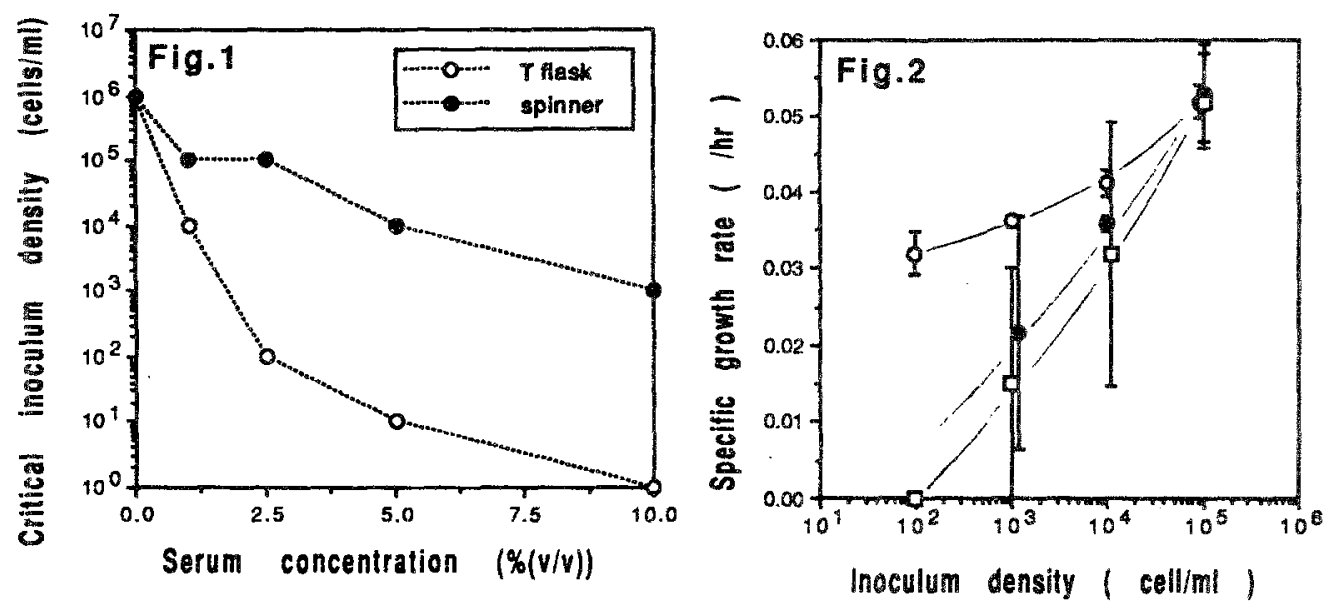

Figure 1: Critical inoculum density required for cell growth. Cell growth was not obtained under conditions that fall below the curves shown. The cID required for growth at 100 rpm was identical to that at $200 \mathrm{rpm}$.

Figure 2: Specific MAb production rates versus specific growth rates obtained at various culture conditions; o. T flask, $\bullet 100 \mathrm{rpm}$, o- $200 \mathrm{rpm}$.

gel particle were monitored photomicroscopically. The cell culture suspension was centrifuged and the supernatant was aliquoted and kept frozen at $-80^{\circ} \mathrm{C}$. IgG2b was determined using an sandwich enzyme linked immunosorbent assay (ELISA) as described previously (Lee et al, 1989). Specific MAb production rate was also calculated as described previously (Lee et al, 1989).

\section{RESULTS AND DISCUSSION}

Effect of serum concentrations, cultivation methods, and mechanical agitation on cID Exponentially growing cells were inoculated into T flasks (or 6 well plates) and spinner flasks containing media with different serum concentrations. Inoculum densities ranging from 1 to $10^{6}$ cells $/ \mathrm{ml}$ were used. Critical inoculum density (cID) is the minimum inoculum density required for cell growth at certain culture conditions. Cells at low inoculum density required higher serum concentration for cell growth than in high inoculum density irrespective of cultivation methods (Fig. 1). In a static culture (T flasks or 6 well plates) with $10 \%$ serum medium, cells could grow at the inoculum density of $1 \mathrm{cell} / \mathrm{ml}$. Cloning efficiency under this condition was about $75 \%$. When $5 \%$ serum containing medium was used, the cID for cell growth was 10 cells $/ \mathrm{ml}$, and increased to $10^{4}$ cells $/ \mathrm{ml}$ in $1 \%$ serum medium. Successful growth in medium without serum required a cID of $10^{6}$ cells $/ \mathrm{ml}$. This result indicates that by increasing inoculum density, cells can overcome reduced mitogenic stimulation caused by reduced serum concentrations.

Cells in suspension culture (spinner flasks) required higher serum concentration for growth than in a static culture when a low inoculum density was used. Two different agitation speeds used (100 and $200 \mathrm{rpm}$ ) affected the specific growth rate (Fig. 2), but not cID at various culture conditions (Fig. 1). Cells in an agitated culture with $10 \%$ serum medium needed a cID of $10^{3}$ cells $/ \mathrm{ml}$ while cells in a static culture needed only 1 cell $/ \mathrm{ml}$ as a $\mathrm{cID}$. Although cID varies among cell lines, the observation that cells in agitated culture require higher inoculum density than in static culture is consistent with the data of Velez et al. (1986). However, when the serum concentration was reduced to zero the cID was $10^{6}$ cells $/ \mathrm{ml}$, the same as for T flasks.

The observation that static culture requires a smaller cID than suspension culture has been explained based on cell crowding on the bottom of stationary $T$ flask where the local cell density is high (Dodge and $\mathrm{Hu}, 1986$; Velez et al., 1986). However, it is hard to deduce the local cell density effect on cell growth only by comparing data obtained from $T$ and spinner flasks. This difficulty is due to the fact that cells in spinner flasks are exposed to shear induced by mechanical agitation, and shear sensitivity of cells may be density-dependent (Fig. 2). This is illustrated by 
an experiment in which specific growth rates at two agitation speeds (100 and $200 \mathrm{rpm})$ and in $T$ flasks were obtained at several inoculum densities. The specific growth rates increased as the inoculum density increased from $10^{2}$ to $10^{5}$ cells $/ \mathrm{ml}$ both for cultivation in $\mathrm{T}$ and spinner flasks (Fig. 2). As the inoculum density increased from $10^{2}$ cells $/ \mathrm{ml}$ to $10^{5}$ cells $/ \mathrm{ml}$, specific growth rate increased from 0.031 to $0.051 \mathrm{hr}^{-1}$ for cultivation in $T$ flasks. In spinner flasks the growth rate was essentially zero at an inoculum density of $10^{2}$ cells $/ \mathrm{ml}$ and increased to $0.053 \mathrm{hr}^{-1}$ at an inoculum density of $10^{5}$ cells $/ \mathrm{ml}$. Specific growth rates in T flasks were consistently higher than in spinner flasks with more pronounced differences at low inoculum densities. However, as inoculum size increased, the difference in growth rates obtained between $\mathrm{T}$ and spinner flasks diminished and became insignificant at $10^{5} \mathrm{cells} / \mathrm{ml}$. Cells agitated at $200 \mathrm{rpm}$ showed the same specific growth rate as cells grown in $\mathrm{T}$ flask both inoculated at the inoculum density of $10^{5}$ cells $/ \mathrm{ml}$. Cells at high inoculum density are found to be less sensitive to shear induced by mechanical agitation than cells at low inoculum density.

If these cells do produce aGFs, their concentration at high inoculum densities may be high enough to compensate for reduction in growth factors resulting from the lower serum levels. Autostimulation of cell growth due to higher inoculum densities would also lead to higher concentrations of aGFs that could overcome the detrimental shear effects. Cells placed in low serum and serum-free media have been reported to be more sensitive to shear than cells placed in high serum media (Murakami et al, 1983; Lee et al., 1989a; McQueen and Bailey, 1989; Kunas and Papoutsakis, 1989, 1990; Shacter, 1989; Pol et al., 1990).

To assess further the effect of local cell density on cell growth, an experiment was performed using entrapped cells. Entrapped cells were inoculated into $\mathrm{T}$ flasks at the inoculum density of 800 cells $/ \mathrm{ml}$ in $1 \%$ serum containing medium. Cells in static culture could not grow under similar conditions (Fig. 1). The local cell density of entrapped cells was approximately $2 \cdot 10^{5}$ cells per milliliter of calcium alginate beads. The entrapped cells in alginate beads could grow under this condition (Fig. 3). Thus, local cell density appears to be more important for cell growth than the overall cell density. These observations are consistent with the aGF model in which high local concentrations of aGFs lead to increased cell growth.

aGFs in hybridoma cells have not been studied in detail. IL-1 and IL-6 may be aGFs in hybridoma cells. Recent studies have shown that IL-1 (Sakai et al, 1987) and IL-6 (Kawano et al., 1988) may be aGFs in leukemia cells and human myeloma cells, respectively.

Specific MAb production rate In order to optimize MAb production, the relationship between specific MAb production rate and specific growth rate must be understood. Specific MAb production rates were obtained under all experimental conditions described above except for the immobilized cells. Although specific growth rate appeared to be dependent on cultivation methods and inoculum density, specific MAb production rate was independent of cultivation method and inoculum density (Fig. 4). The specific MAb production rates were slightly elevated at lower specific growth rates. This observation is consistent with a growing body of evidence that shows that low specific growth rates promote higher MAb production rates under certain conditions (Reuveny et al., 1986; Dean et al., 1987; Maiorella et al., 1989; Hagedorn and Kargi, 1990; Heath et al., 1990; Lee and Palsson, 1990a). This apparent uncoupling of specific MAb production rate from specific growth rate implies that immobilized hybridoma cells with low growth rates can be used for $\mathrm{MAb}$ production.

In conclusion, the observations made in this report are phenomenologically consistent with the production of aGFs by hybridoma cells. The design of culture systems to take advantage of these aGFs may lead to improved economics of MAb production. Even though we have not unambiguously demonstrated the presence of a particular aGF, taken together our results argue for immobilization as an economical alternative to large-scale cultivation of hybridoma cells for MAb production.

Acknowledgements The authors thank Ms. Elaine Vong for her technical assistance. This work was supported by National Science Foundation (EET-8712756 and BCS-9009389).

\section{REFERENCES}

Balkwill, F.R. Cytokines in Cancer Therapy. Oxford University Press: Oxford, 1989; pp. 174-181.

Bergman, Y.; Haimovich, J. Eur. J. Immunol. 1977, 7, 413-417.

Cooper, G. M. Oncogenes. Jones and Bartlett Publishers, Inc.: Boston, MA, 1990; pp 163-173. Dean, Jr., R. C.; Karkare, S. B.; Ray, N. G.; Rundstadier, Jr., P. W.; Venkatasubramanian, K. 


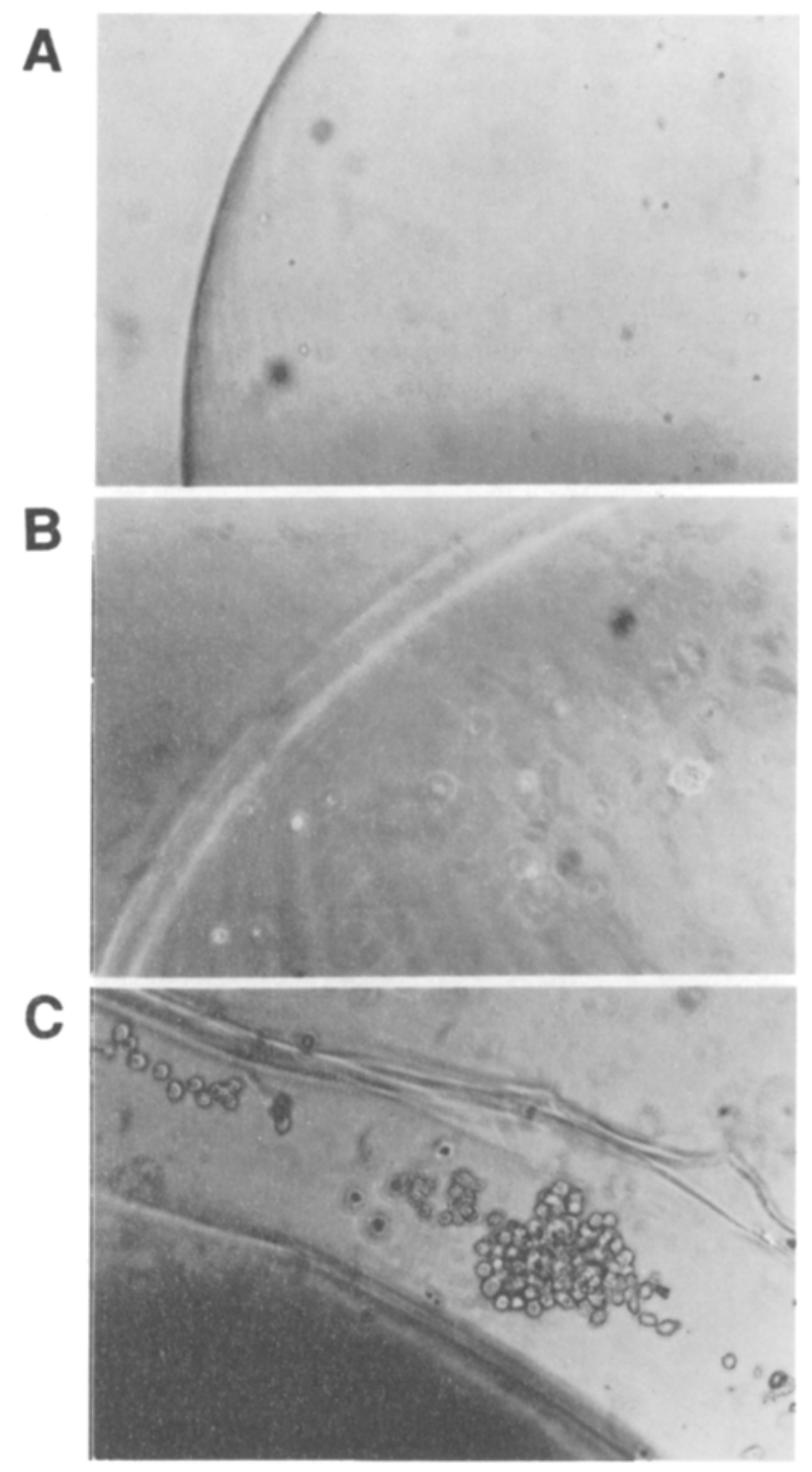

Figure 3: Photomicrograph of immobilized cells. (A) 0 day, (B) 10 day, and (C) 20 day. Photomicrographs (A) \& (B) were taken at 40x magnification and photomicrograph (C) was taken at $100 \mathrm{x}$ magnification. 


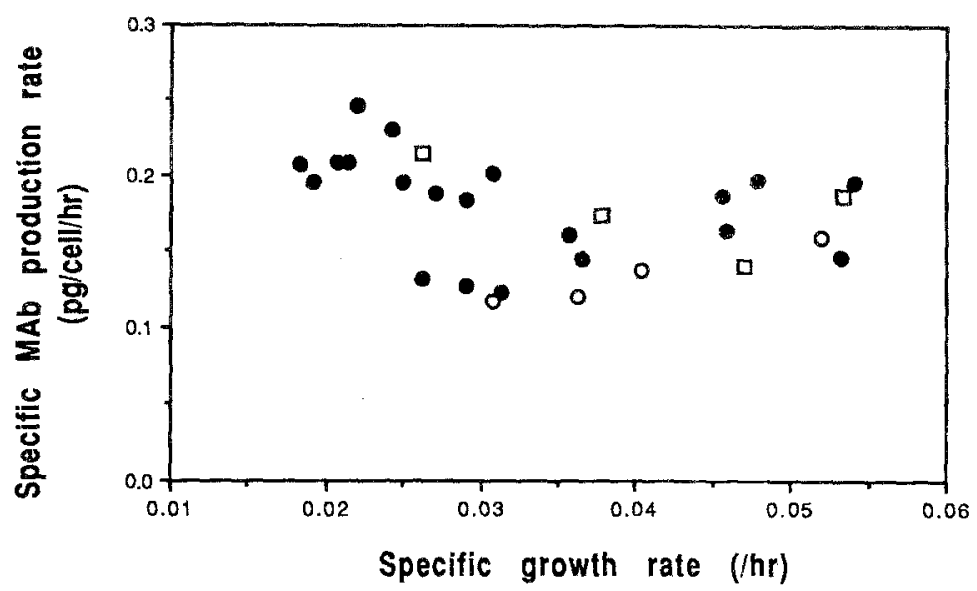

Figure 4: Specific growth rates obtained at various agitation speeds; 0 T flask, $100 \mathrm{rpm},-\square$ $200 \mathrm{rpm}$. Cells at lower inoculum density and under higher agitation speed are more sensitive to culture conditions resulting in larger standard deviations than cells at higher inoculum density and lower agitation speed.

Ann. N. Y. Acad. Sci., 1987, 506, 129-146.

Dodge, T. C.; Hu, W. S. Biotechnol. Lett. 1986, 8, 683-686.

Hagedorn, J.; Kargi, F. Biotechnol. Prog., 1990, 6, 220-224.

Heath, C.; Dilwith, R.; Belfort, G. J. Biotechnol. 1990, 15, 71-90.

Hirano, T.; Yasukawa, K.; Harada, H.; Taga, T.; Watanabe, Y.; Matsuda, T.; Kashiwamura, S.;

Nakajima, K.; Koyama, K.; Iwamatsu, A.; Tsunasawa, S.; Sakiyama, F.; Matsui, H.;

Takahara, Y.; Taniguchi, T; Kishimoto, T. Nature. 1986, 324, 73-76.

Kiwano, M.; Hirano, T.; Matsuda, T.; Taga, T.; Horii, Y.; Iwato, K.; Asaoku, H.; Tang, B.;

Tanabe, O.; Tanaka, H.; Kuramoto, A.; Kishimoto, T. Nature. 1988, 332, 83-85.

Kunas, K. T.; Papoutsakis, E. T. Biotechnol. Lett., 1989, 11, 525-530.

Kunas, K. T.; Papoutsakis, E. T. J. Biotechnol, 1990, 15, 57-69.

Lee, G. M.; Huard, T. K.; Palsson, B. O. Biotechnol. Lett. 1988, 10, 307-312.

Lee, G. M.; Huard, T. K.; Kaminski, M. S.; Palsson, B. O. Biotechnol. Leth. 1988a, 10, 625-628.

Lee, G. M.; Huard, T. K.; Palsson, B. O. Hybridoma 1989, 8, 369-375.

Lee, G. M.; Savinell, J. M.; Palsson, B. O. Hybridoma 1989a, 8, 639-645.

Lee, G. M.; Palsson, B. O. Biotechnol. Technique 1990, 4, 341-344.

Lee, G. M.; Palsson, B. O. Biotechnol. Bioeng. 1990a, 36, 1049-1055.

Maiorella, B.; Howarth, B.; Shauger, A.; Inlow, D. Optimized pH control for antibody production. Presented at ACS National Meeting, Miami, FL, 1989.

McQueen, A.; Bailey, J. E. Biotechnol. Lett., 1989, 11, 531-536.

Murakami, H.; Masui, H.; Sato, G. Suspension culture of hybridoma cells in serum-free medium: soybean phospholipids as essential components. In Growth of Cells Hormonally Defined Media; G. Sato, A. Pardee, D. Sinbasku, Eds.; Cold Spring Harbour Laboratories, Cold Spring

Harbour: New York, 1982; pp 711-715.

Petersen, J. F.; McIntyre, L. V.; Papoutsakis, E. T. J. Biotechnol 1988, 7, 229-246.

Pol, L.; Zijlstra, G.; Thalen, M.; Tramper, J. Bioprocess Engr., 1990, 5, 241-245.

Ozturk, S. S.; Palsson. B. O. J. Biotechnol. 1990, 16, 259-278.

Reuveny, S.; Velez, D.; Miller, L.; MacMillan, J. D. J. Immunol. Methods, 1986, 86, 61-69.

Sakai, K.; Hattori, T.; Matsuoka, M.; Asou, N.;Yamamoto, S.; Sagawa, K.; Takatsuki, K. J. Exp. Med. 1987, 166, 1597-1602.

Shacter, E. Trends Biolechnol., 1989, 7, 248-253

Sporn, M. B.; Roberts, A. B. Nature 1985, 313, 745-747.

Tharakan, J. P.; Chau, P. C. Biotechnol. Lett. 1986, 8, 457-462.

Velez, D.; Reuveny, S.; Miller, L.; Macmillan, J. D. J. Immunol. Methods 1986, 86, 45-52. 